\title{
An Overview of the GI Fellowship Interview: Part II-Tips for Selection Committees and Interviewers
}

\author{
Rashmi Advani ${ }^{1}$ - Steven Bollipo ${ }^{2,3} \cdot$ Aline Charabaty $^{4} \cdot$ Nikki Duong $^{5} \cdot$ Mohammad Bilal $^{6} \cdot$ Keith Siau $^{7}$. \\ Samir C. Grover ${ }^{8,9}$
}

Accepted: 14 January 2022 / Published online: 5 February 2022

(c) The Author(s), under exclusive licence to Springer Science+Business Media, LLC, part of Springer Nature 2022

Keywords Gastroenterology · Interview · Fellowship · Interviewer · Interviewee $\cdot$ Education · Continuous quality improvement

\section{Introduction}

The gastroenterology (GI) fellowship interview is a highstakes process that determines whether a person embarks on a journey to become a gastroenterologist [1]. Program directors and selection committees for GI fellowships have the difficult task of selecting applicants that, upon completion of training, are capable of high-quality clinical practice, a process that involves assessing and selecting applicants on the basis of clinical performance, academic achievement, communication skills, and other criteria relevant to success in the profession. Programs not only have an obligation to ensure that fellowship positions are allocated fairly through an objective selection process but also have a societal obligation to produce a diverse pool of new gastroenterologists through a process that ensures that equity, diversity and inclusivity are prioritized [2].

Keith Siau and Samir C. Grover contributed equally to this manuscript.

Rashmi Advani

Rashmi.advani@stonybrookmedicine.edu

1 Division of Gastroenterology and Hepatology, Stony Brook University Hospital, Renaissance School of Medicine at Stony Brook, 101 Nicolls Road, HSC T17-060, Stony Brook, NY 11794-8173, USA

2 School of Medicine and Public Health, University of Newcastle, Callaghan, NSW, Australia

3 Department of Gastroenterology, John Hunter Hospital, Newcastle, NSW, Australia

4 Division of Gastroenterology, Johns Hopkins School of Medicine, Johns Hopkins-Sibley Memorial Hospital, Washington, DC, USA
In this article, we (the authors) provide advice to program directors and selection committee members on how to develop selection, interview, and ranking processes that facilitates achieving these goals. We also discuss the programmatic considerations for underrepresented applicants such as women, LGBTQ + (lesbian, gay, bisexual, transgender, queer, intersex, and asexual), and underrepresented minorities (URM).

\section{Defining the Selection Processes}

A fellowship program should have a transparent process for selecting its fellows that is in alignment with its identified goals and objectives [3] that starts with a review of the goals of the fellowship program, which are used to establish a consensus of criteria used to select fellows. For example, programs with goals of training clinician-scientist gastroenterologists and those aiming to train gastroenterologists

5 Division of Gastroenterology, Hepatology and Nutrition, Virginia Commonwealth University, Richmond, VA, USA

6 Minneapolis VA Medical Center, University of Minnesota, Minneapolis, MN, USA

7 Department of Gastroenterology, Royal Cornwall Hospitals NHS Trust, Truro, UK

8 Division of Gastroenterology and Hepatology, University of Toronto, Toronto, ON, Canada

9 Li Ka Shing Knowledge Institute, St. Michael's Hospital, University of Toronto, Toronto, ON, Canada 
for rural clinical practice may have significantly different selection criteria.

The program should identify which data it will be using as part of the selection process. Data available to selection committees are typically standardized from application platforms such as the Electronic Residency Application Service (ERAS) in the USA and the Canadian Residency Matching Service (CaRMS) in Canada. Elements include personal statements, curriculum vitae (CV), past academic records, standardized examination scores, letters of recommendation (LoR) and Dean's letters [4].

The selection process should identify the weight of each component, the number of independent assessments, and how the rank list will be generated. Typical marking schemes for applicant dossiers include assessments of performance in clinical medicine or gastroenterology, academic work including research, and consolidation of a career plan into the personal statement [4].

Individuals involved in the assessment of applicants should have diverse representation and a breadth of functions in the fellowship program. Participants may include clinicians who serve as educators, administrators and researchers, current trainees, and allied health professionals who work closely with the GI program, such as endoscopy nurses or technicians. They should be trained for the selection process including technical aspects of the data portals and virtual interview systems, criteria for selection, and assessment instruments being used.

So that the applicants are adequately prepared for the application process, details of the selection processes and the types of metrics used to evaluate the applicants must be transparent, available to them, and frequently updated, preferably on the program or match website. An example of a typical selection process is shown in Fig. 1.

\section{Dossier Review and Shortlisting of Candidates}

We recommend that multiple independent individual assessments of each candidate dossier should be completed by the reviewers, a system that generates reliable and consistent rankings of candidates [3]. Scores should be assigned on the basis of demonstrable skills or behaviors assessed in the application documents [3], that may include cognitive skills and knowledge, problem solving and patient management skills, or behavior and attitudinal skills. As an example, Table 1 contains elements used for grading of personal letters by the Canadian Residency Matching Service (CaRMS) for fellowship programs in Canada [2].

Programs can estimate the number of candidates to shortlist by reviewing the rank of the candidates who successfully matched during prior selections, and the selection committee's capacity for interviews [5].

Table 1 Recommendations from the CaRMS for assessment metrics for letters of reference

\section{Cognitive skills and knowledge}

Problem solving and patient management skills

Behavior and attitudinal skills

Communication skills and working relationships

Motivation and punctuality

Sense of responsibility

Procedural skills specific to the discipline

Special qualities and unique contributions
Fig. 1 Schematic demonstrating the typical fellowship selection process, adapted from the Association of American Medical Colleges' (AAMC) Best Practices for Conducting Residency Program Interviews [12]

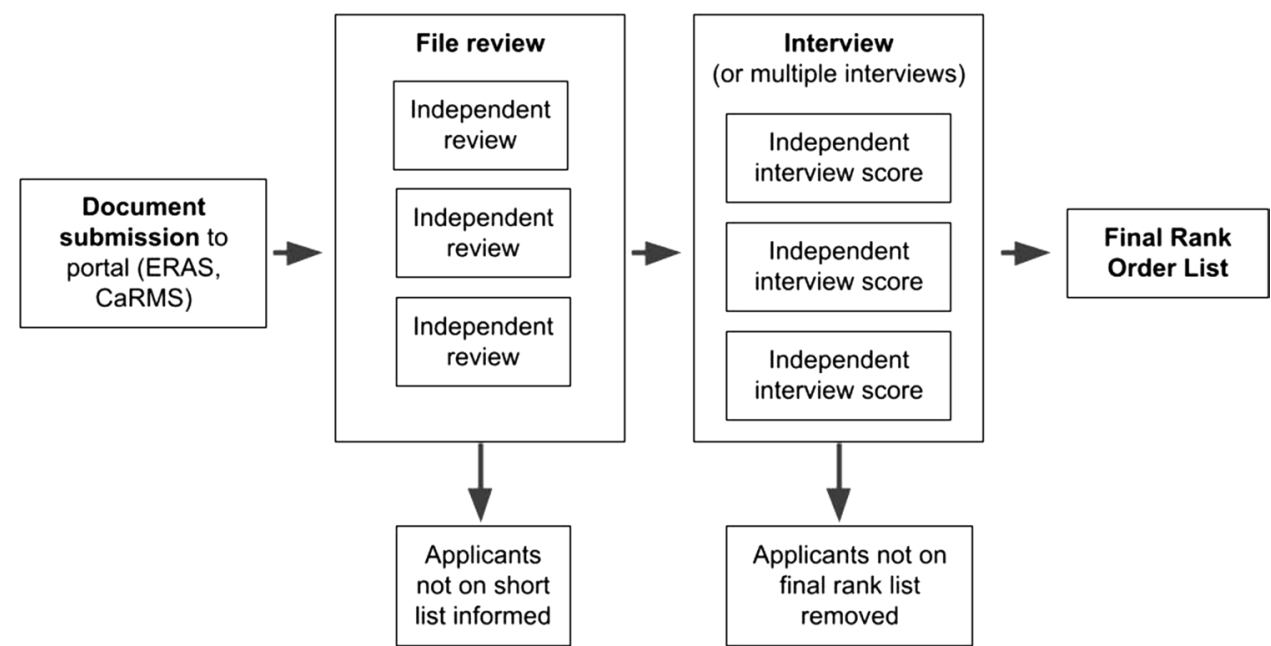




\section{Interview Planning and Interview Format}

Fellowship programs in gastroenterology use several interview formats, including panels with multiple interviewers, tandem interviews with two interviewers, and one-on-one interviews. There is no consensus regarding which format is preferred. Regardless of interview format, we recommend having multiple independent interviewer scores in order to maximize reliability and consistency [2].

Programs should be cognizant of the economic burden of travel and lodging incurred by candidates [6]. Virtual interviews, which have become commonplace during the COVID-19 pandemic, have reduced these time and financial burdens [7]. For GI fellowships, virtual interviews have been received positively by participants and programs, with positive comments referencing flexibility, cost saving, convenience, and the option for interviewing at a larger number of programs [8-10]. Organization of the timing of interviews among programs may also be useful; for example, in Canada, GI residency programs coordinate interview dates in a way that minimizes travel across the country [11]. Videos or live-streams of program tours, or virtual reality programs [12] may provide candidates with an alternative to in-person tours [13].

Both unstructured and structured interview formats have been used in fellowship selection [10]. Unstructured interviews consist of free-form questions chosen by the interviewer depending on the content of the applicant's dossier. Structured interviews, in contrast, enhance the standardization of the interview by ensuring all candidates are asked the same thematic questions. There is mixed literature on whether structured interviews improve the reliability of interview processes $[14,15]$. Structured interviews however may limit interviewers from in-depth exploration of specific content in the application.

\section{Types of Interview Questions}

The questions asked to candidates should be relevant jobspecific questions mostly with regard to the responsibilities of the trainee or future attending in gastroenterology [16]. Certain types of interview questions have been studied broadly in selections as to their reliability and validity:

Behavioral questions attempt to predict future behavior on the basis of recollection of previous behavior. These questions usually ask the candidate to describe a situation, the action taken by the candidate, and the resultant consequence. For example, a candidate may be asked to describe an instance when their clinical opinion differed from that of the attending physician [16].
Situational questions ask candidates to describe how they would handle hypothetical future scenarios. They are based on the hypothesis that future behaviors are predicated on current intentions. For example, a candidate may be asked what they would do if a junior resident was bullied by a colleague [16].

Cognitive questions ask candidates about knowledge relevant to gastroenterology. They are based on the premise that knowledge of the specialty predicts interest or performance in the discipline. For example, a candidate may be asked how to classify colonic polyp morphology. Nonetheless, there is little consensus that cognitive questions are predictive of superior residency performance [17].

Interviewers should absolutely refrain from questions that discriminate on the basis of race, color, sex, age, religion, sexual orientation, national origin, or disability. This includes discrimination on the basis of pregnancy and childrearing plans. Furthermore, program should refrain from asking identifying information about the other programs or specialties to which the applicant has applied [6].

We recommend an approach similar to the Association of American Medical Colleges' (AAMC) Best Practices for Conducting Residency Program Interviews [16], as shown in Fig. 2, wherein program develop behavioral or situational questions in a manner that assigns them to specific competencies or fellow roles.

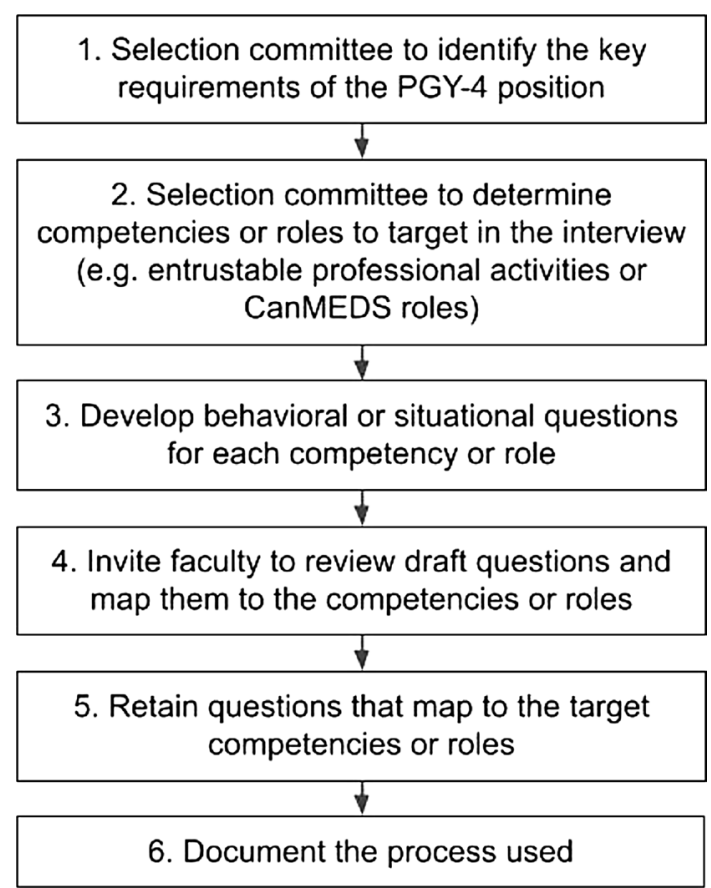

Fig. 2 Key steps for development of behavioral and situational type interview questions, adapted from the Association of American Medical Colleges' (AAMC) Best Practices for Conducting Residency Program Interviews [16] 


\section{Grading Interview Performance}

The use of a standardized marking scheme for all candidates is recommended as a way in which reliability and consistency in ranking can be maintained $[2,16]$. This scheme should ideally contain metrics that can be used to guide the interviewer who is grading performance. The scheme should be developed and approved by the selection committee in advance.

Candidates typically perform well on the interview if they are able to demonstrate the following:

(a) Provide responses that give confidence that the candidate is competent in all of the required skills and qualities necessary to successfully complete their fellowship such as commitment to the specialty.

(b) Demonstrate an ability to think on their feet, structure answers succinctly and persuasively, and communicate effectively.

(c) Are kind and compassionate, keen to learn, thoughtful, passionate about learning and patient care, and display qualities typical of a future role model and leader.

(d) Convince interviewers that they could become a good colleague, benefit patients, be a good team player, and benefit their institution.

Candidates may perform poorly at the interview if they demonstrate the following:

(a) Probity concerns, for example, when the candidate is unable to provide detail about the achievements listed in their application.

(b) Inability to reflect, such as the inability to answer open questions such as "why do you want to become a gastroenterologist", or poor performance on behavioral or situational questions.

(c) Lack of insight, such as being unaware of one's weaknesses or recognizing when the interview is not going well.

(d) Lack of preparation for the interview.

(e) Poor social skills with limited ability to communicate thoughts and ideas to others.

(f) Marked arrogance, selfishness, and "looking down" on others and on other programs.

(g) Rigidity; inability to adapt to new situations or circumstances or to improvise.

\section{Ranking Candidates}

Ranking of candidates for GI fellowship is inherently subjective. Assessments of the application dossier components and interview performance vary in reproducibility and vary between assessors [17]. Maintaining a ranking process that is objective as possible is paramount.

We recommend compiling a summation of dossier review and interview scores from the multiple assessments of the same, in accordance with formulas developed by consensus by the selection committee. As opposed to review of individual components of dossiers, programs can consider trait-based ranking schemata [18]. This approach, where the entire candidate dossier and interview is globally ranked on the basis of pre-defined traits of relevance to success in gastroenterology (such as leadership, communication and compassion), enables programs to integrate core program values directly into selection criteria, and may be more reliable than piecemeal reviews of each dossier element [18].

We do not recommend that programs hold rank meetings that may influence the rank list with information brought in outside of the interview package or by arbitrarily changing the rank order list [2]. Rank order lists should be generated on the basis of best performance of candidates, not by likelihood of the candidate matching to the program.

\section{Underrepresented Minorities (URM), Women, and LGBTQ + in GI}

Increasing diversity is paramount for fostering inclusion, equity, and advancement in gastroenterology. Programs should aim to promote a diverse and inclusive fellowship program, faculty, and staff. Program leadership and faculty should actively seek ways to increase URM, LGBTQ+, and female representation in GI.

From 2017 to 2021, although the number of Black/African American and Hispanic/Latino residency applicants increased by approximately $32 \%$ and $18 \%$, respectively, both groups still remain under $<10 \%$ in the 2021 ERAS applicant pool [19].

Based on AAMC data from 2019, 3.8\% of graduating medical students identified as gay or lesbian [19]. Though the number of practicing gastroenterology and/or hepatology physicians who identify as LGBTQ + is unknown, this number is likely a small proportion of the graduating medical student cohort.

In order to accomplish these goals, programs should execute and instill tangible processes that pay close attention to applicants who are female and/or are from URM and LGBTQ + backgrounds. Programs should also consider alternate entry streams for underrepresented groups.

\section{Continuous Process Improvement}

Despite the best efforts of programs to maintain objective, valid and reliable methods for choosing candidates, selection processes do not necessarily predict those who 
perform well in training [20-22]. Fellowship programs should continuously review the performance of their selection processes after the match is completed, modifying the process based on this review. We recommend a review of rank list performance, job descriptions of recent graduates, and whether the selection criteria selected fellows aligned with the goals of the selection process as part of an iterative process aimed at constantly refining and improving the fellowship selection method. Finally, we recommend that identified best practices should be shared among other programs or disseminated in the literature in order to further refine the process.

\section{Conclusion}

We offer these recommendations with the aspiration that they increase objectivity and transparency in fellowship selection processes and improve diversity and inclusivity in the cohort of future gastroenterologists with the ultimate goal of graduating fully-trained gastroenterologists who display all of the qualities that comprise a caring, skillful, and effective specialist physician. We also are hopeful that this article encourages debate toward establishment and adoption of best practices aimed at fairly selecting gastroenterology fellows.

\footnotetext{
Author contributions Rashmi Advani, MD, DABOM (study concept; literature review, drafting of manuscript). Steven Bollipo, FRACP (study concept; literature review, critical revision of manuscript for important intellectual content). Aline Charabaty, MD, AGAF, FACG (literature review, critical revision of manuscript for important intellectual content). Nikki Duong, MD (literature review, drafting of manuscript). Mohammad Bilal, MD (critical revision of manuscript for important intellectual content). Keith Siau, MBChB, MRCP (study supervision, literature review, drafting of manuscript, critical revision of manuscript for important intellectual content). Samir C. Grover, MD, MEd, FRCPC (study supervision, literature review, drafting of manuscript, critical revision of manuscript for important intellectual content).
}

Funding None.

\section{Declaration}

Conflict of interest Rashmi Advani has no conflicts of interest to disclose. Nikki Duong has no conflicts of interest to disclose. Mohammad Bilal has no conflicts of interest to disclose. Keith Siau has no conflicts of interest to disclose. Steven Bollipo has no conflicts of interest to disclose. Aline Charabaty is on the Advisory board/consulting for Abbvie, Janssen, Takeda, Pfizer, BMS. She is the Creator of @ MondayNightIBD and Co-Creator of Scrubs \& Heels, LLC. Samir C. Grover has received research grants and personal fees from AbbVie and Ferring Pharmaceuticals, personal fees from Takeda, education grants from Janssen, and has equity in Volo Healthcare.

\section{References}

1. Duong N, Aby ES, Hathorn KE, Simons-Linares CR, Bilal M. How to become a competitive applicant for gastroenterology fellowship: tips and tricks for success part II. Dig Dis Sci 2020;65:2172-2175. https://doi.org/10.1007/ s10620-020-06293-4.

2. Bandiera G, Abrahams C, Ruetalo M, Hanson MD, Nickell L, Spadafora S. Identifying and promoting best practices in residency application and selection in a complex academic health network. Acad Med 2015;90:1594-1601. https://doi.org/10. 1097/acm.0000000000000954.

3. Jordan J, Sternberg K, Haas MRC, He S, Yarris LM, Chan TM, Deiorio NM. Reimagining residency selection: part 3-a practical guide to ranking applicants in the post-COVID-19 era. J Grad Med Educ 2020;12:666-670. https://doi.org/10.4300/ JGME-D-20-01087.1.

4. Paterson QS, Hartmann R, Woods R, Martin LJ, Thoma B. A transparent and defensible process for applicant selection within a Canadian emergency medicine residency program. CJEM 2020;22:215-223. https://doi.org/10.1017/cem.2019.460.

5. Collins M, Curtis A, Artis K, Staib L, Bokhari J. Comparison of two methods for ranking applicants for residency. J Am Coll Radiol 2010;7:961-966. https://doi.org/10.1016/j.jacr.2010.06. 020.

6. Fogel HA, Liskutin TE, Wu K, Nystrom L, Martin B, Schiff A. The economic burden of residency interviews on applicants. Iowa Orthop J 2018;38:9-15.

7. Zaki MM, Nahed BV. Utilizing virtual interviews in residency selection beyond COVID-19. Acad Med 2020;95:e7-e8. https:// doi.org/10.1097/ACM.0000000000003589.

8. Daram SR, Wu R, Tang SJ. Interview from anywhere: feasibility and utility of web-based videoconference interviews in the gastroenterology fellowship selection process. Am J Gastroenterol 2014;109:155-159. https://doi.org/10.1038/ajg.2013.278.

9. Hamade N, Bhavsar-Burke I, Jansson-Knodell C, Wani S, Patel SG, Ehrlich AC, Paine E, Hosseini-Carroll P, Menard-Katcher $\mathrm{P}$, Fayad N. Virtual gastroenterology fellowship recruitment during COVID-19 and its implications for the future. Dig Dis Sci. 2021. https://doi.org/10.1007/s10620-021-07014-1.

10 Barnes EL, Grimm-Vavlitis JL, Long MD. Impact of virtual interviews on gastroenterology and hepatology fellowship recruitment. Dig Dis Sci. 2021. https://doi.org/10.1007/ s10620-021-07123-x.

11. Kroeker K, Personal Correspondence; 2021.

12. Zertuche JP, Connors J, Scheinman A, Kothari N, Wong K. Using virtual reality as a replacement for hospital tours during residency interviews. Med Educ Online 2020;25:1777066. https://doi.org/10.1080/10872981.2020.1777066.

13. Cappell MS. Novel modifications for a virtual interview visit to simulate the traditional, live, site visit for GI fellowship applicants for an academic GI fellowship program due to the COVID-19 pandemic. Dig Dis Sci 2021;66:1370-1371. https:// doi.org/10.1007/s10620-020-06741-1.

14. Blouin D, Day AG, Pavlov A. Comparative reliability of structured versus unstructured interviews in the admission process of a residency program. J Grad Med Educ 2011;3:517-523. https:// doi.org/10.4300/JGME-D-10-00248.1.

15. Blouin D. Reliability of a structured interview for admission to an emergency medicine residency program. Teach Learn Med 2010;22:246-250. https://doi.org/10.1080/10401334.2010. 511979.

16. Best Practices for Conducting Residency Program Interviews. Washington DC: Association of American Medical Colleges; 2016. 
17. Naides AI, Ayyala HS, Lee ES. How do we choose? A review of residency application scoring systems. J Surg Educ 2021;78:1461-1468. https://doi.org/10.1016/j.jsurg.2021.02.003.

18 Gawad N, Younan J, Towaij C, Raiche I. Comparing 2 approaches for the dossier review of residency applications. J Grad Med Educ 2021;13:240-245. https://doi.org/10.4300/JGME-D-20-00619.1.

19. ERAS Statistics. Data \& Reports. Association of American Medical Colleges. https://www.aamc.org/data-reports/interactive-data/ eras-statistics-data. https://www.aamc.org/media/39341/downl oad; 2021 Accessed 14.12.21.

20. Stephenson-Famy A, Houmard BS, Oberoi S, Manyak A, Chiang S, Kim S. Use of the interview in resident candidate selection: a review of the literature. J Grad Med Educ 2015;7:539-548.
21. Gordon EKB, Clapp JT, Heins SJ, Gaulton TG, Lane-Fall MB, Aysola J, Baranov DY, Fleisher LA. The role of the interview in residency selection: A mixed-methods study. Med Educ 2020;54:1029-1039. https://doi.org/10.1111/medu.14248.

22. Baker $\mathrm{K}$. The tip of the iceberg: improving the quality of rank order lists for the match. Acad Med 2013;88:1206-1208. https:// doi.org/10.1097/ACM.0b013e31829ed3eb.

Publisher's Note Springer Nature remains neutral with regard to jurisdictional claims in published maps and institutional affiliations. 